\title{
What is your opinion of the present-day condition of philosophy in Russia?
}

(C) Springer Science+Business Media Dordrecht 2014

The question is answered by:

Abdusalam Guseynov, DPhil, Professor, Full member of the Russian Academy of Sciences, Director of the RAS Institute of Philosophy, Head of Chair of Ethics at Lomonosov Moscow State University. (doi:10.1007/s11212-014-9216-z)

Vladimir Porus, DPhil, Full Professor, Head of Chair of Philosophy, HSE NRU. (doi:10.1007/s11212-014-9217-y)

Valery Savchuk, DPhil, Professor, Head of the Media Philosophy Research Centre at the St. Petersburg State University's Department of Philosophy, Member of the International Association of Historians of Arts and Art Critics, Member of Russia's Artists' Union, Member of the Free Culture Community and the 10 Pushkinskaya St. Community. (doi:10.1007/s11212-014-9218-x)

Vladimir Mironov, DPhil, Corresponding Member of the RAS, Dean of the Department of Philosophy, Lomonosov Moscow State University. (doi:10.1007/ s11212-014-9219-9)

Fyodor Girenok, Professor at the Department of Philosophy, Lomonosov Moscow State University. (doi:10.1007/s11212-014-9220-3)

Aleksei Rutkevich, DPhil, Professor, Dean of the Department of Philosophy, HSE NRU. (doi:10.1007/s11212-014-9221-2)

Vladislav Lektorsky, DPhil, Full member of the Russian Academy of Sciences, Full member of the Russian Academy of Education, Department Head of the RAS IPh. (doi:10.1007/s11212-014-9222-1) 